\title{
A PROTEÇÃO DOS DIREITOS FUNDAMENTAIS NO REGISTRO CIVIL DAS PESSOAS NATURAIS
}

\section{THE PROTECTION OF FUNDAMENTAL RIGHTS IN NATURAL PERSONS CIVIL REGISTRY}

Eloy Pereira Lemos Junior eloy.junior@uol.com.br

Débora de Freitas Palhares deborafreitaspalhares@yahoo.com.br

Recebido: 11-12-2017

Aprovado: 27-5-2019

SUMÁRIO: 1 Introdução. 2 os direitos e garantias constitucionais fundamentais no contexto do Estado Democrático de Direito. 30 registro civil das pessoas naturais como um direito coletivo. 40 registro civil das pessoas naturais e o seu papel na efetividade dos direitos fundamentais. 4.1 Registro de Nascimento. 4.1.1 Convênio entre o serviço de Registro Civil de Pessoas Naturais e a maternidade e o Provimento 13 do CNJ. 4.2 Registro de Casamento. 4.3 Registro de Óbito. 4.4 A imunidade dos emolumentos do registro de nascimento e óbito e a primeira via da certidão respectiva. 5 Consideraçóes Finais. 6 Referências.

\section{RESUMO:}

$\mathrm{O}$ artigo visa apontar os documentos oficiais de Registro Civil como meios de aplicação efetiva de cidadania correspondente à aplicação do Princípio da Dignidade da Pessoa Humana a partir da aplicação de seus atos destinados ao indivíduo. Cabe mencionar, portanto, que os referidos atos oficiais devem coadunar com a proteçấo aos direitos fundamentais. Daí a ideia da necessidade de desburocratização dos trâmites cartorários, de modo a propiciar um amplo acesso aos direitos inerentes à pessoa humana, sejam eles o nome, registro matrimonial, registro de óbito, entre outros. Busca-se, para construção do presente artigo, asseverar a necessidade de fortalecimento dos serviços

\section{ABSTRACT:}

The article aims to point out the official documents of Civil Registry as means of effective application of citizenship corresponding to the application of the Principle of the Dignity of the Human Person from the application of his acts destined to the individual. It should be mentioned, therefore, that these official acts must be consistent with the protection of fundamental rights. Hence, the idea of reducing the bureaucracy of registry office procedures, in order to provide broad access to the rights inherent to the human person, be they name, matrimonial registration, death registration, among others. The purpose of this article is to assert the need to strength- 
registrais e sua estruturação como avanço no reconhecimento dos direitos fundamentais e sua materialização, objetivo primordial de um Estado Democrático de Direito como o Brasil, o que demonstra a relevância da temática. Valeu-se do método de estudo dedutivo, além da pesquisa bibliográfica documental como instrumentos basilares para realização do presente trabalho.

\section{Palavras-chave:}

Direitos Fundamentais; Dignidade da Pessoa Humana; Registro Civil das Pessoas Naturais. en registration services and structure them as an advance in the recognition of fundamental rights and their materialization, the primary objective of a Democratic State of Law as Brazil, which demonstrates the relevance of the subject. It was based on the method of deductive study, in addition to the documentary bibliographical research as basic instruments for the accomplishment of the present work.

\section{Keywords:}

Fundamental rights; Dignity of Human Person; Civil Registry of Individuals.

\section{INTRODUÇÃO}

O presente artigo tem por finalidade verificar a importância do Registro Civil das Pessoas Naturais na sociedade demonstrando que os registros nele realizados são considerados um direito fundamental de todo ser humano, daí a elevada relevância social e jurídica, motivo de debates políticos e grandes inovaçóes legislativas, no sentido de facilitar e incentivar o acesso da população ao Cartório de Registro Civil das Pessoas Naturais.

A metodologia utilizada na realização deste trabalho foi o método dedutivo, utilizando-se da pesquisa bibliográfica documental, com destaque para doutrinas, artigos e jurisprudências, visando ao esclarecimento do que há de mais relevante no que concerne à proteção dos direitos fundamentais no registro civil das pessoas naturais.

O trabalho apresenta três capítulos, além da introdução e conclusão, divididos em: os direitos e garantias constitucionais fundamentais no contexto do Estado Democrático de Direito; o registro civil das pessoas naturais como um direito coletivo; o registro civil das pessoas naturais e o seu papel na efetividade dos direitos fundamentais; destacando, neste último capítulo, o registro de nascimento, o registro de casamento, o registro de óbito e as imunidades dos emolumentos do registro de nascimento e óbito e a primeira via da certidão respectiva.

Destaca-se o registro civil das pessoas naturais como um representante da proteção dos direitos fundamentais, na medida em que tais serviços prestados possui relevância universal, ou seja - de interesse de todos -, sem distinção, e tem como foco principal a salvaguarda do homem e sua dignidade. Desta forma, objetivou-se desenvolver um trabalho que demonstre a importância e o valor do registro civil das pessoas naturais, que busca, através de seus atos, a efetivaçáo da dignidade da pessoa humana. 


\section{OS DIREITOS E GARANTIAS CONSTITUCIONAIS FUNDAMENTAIS NO CONTEXTO DO ESTADO DEMOCRÁTICO DE DIREITO}

O objetivo principal de um Estado Democrático de Direito atual é garantir, viabilizar e concretizar a todos os direitos indispensáveis ao exercício da dignidade da pessoa humana. O Estado deve garantir o respeito pelos direitos humanos e pelas garantias fundamentais.

Não há como afirmar com precisão quando ocorreu, de fato, o surgimento dos direitos fundamentais. Porém, faz-se certo constatar que os direitos fundamentais, como verdadeiras conquistas evolutivas da sociedade, somente triunfaram no fim do século XVIII, por intermédio das revoluçóes liberais americana e francesa. A Revolução Francesa de 1789, sintetizando seus ideais no tripé: liberdade, igualdade e fraternidade, foi uma das revoluçóes mais importantes para o começo da conquista dos direitos fundamentais.

Para Gregório Peces-Barba Martínez,

O século XVIII é o século das luzes, o tempo dos direitos. Trata-se de momento de maturação do conceito de direito humanos, mesmo que eles não tenham se apresentado com toda a sua complexidade e a plenitude de suas características. No século XIX, tem início a construção intelectual dos direitos sociais, desenvolvidos no século XX, o século de ampliação da proteção para o restante dos direitos e da pessoa situada e concreta. (apud ALMEIDA, 2008, p. 297).

É importante ressaltar que a construção de uma proteção realmente efetiva dos direitos fundamentais ainda encontra-se em desenvolvimento e foi somente a partir do século XVIII que a doutrina dos direitos humanos evoluiu e vem evoluindo.

Direitos fundamentais são aqueles indispensáveis, imprescindíveis à condição humana; são direitos básicos e, portanto, chamados fundamentais, sem os quais se torna impossível viver em sociedade.

Os direitos fundamentais tem as seguintes características, entre outras: historicidade (tratam-se de garantias que se incorporam no patrimônio do titular ao longo do processo de maturação das relaçóes sociais e, umas vez incorporados, tais direitos não podem ser retirados ou limitados); universalidade (alcançam todo ser humano sem distinção); imprescritibilidade (não perecem ou caducam em razão da inércia de seu titular); inalienabilidade (o titular de tais direito não pode deles lançar mão, não se admitindo que deles renuncie).

Conforme se verifica do próprio texto do capítulo I, do título II, da Constituição de 88, "Dos direitos e deveres individuais e coletivos", a Carta Magna rompeu com a visão meramente individualista dos direitos fundamentais, abrangendo assim o direito coletivo, o qual diz respeito aos direitos das massas, direitos transindividuais, cuja titularidade pertence a coletividade de pessoas. O fato de o legislador constituinte de 1988 ter inserido a tutela jurídica do direito coletivo no plano da teoria dos direitos e garantias fundamentais representa uma verdadeira mudança de paradigma no sistema jurídico brasileiro.

Afirmativa errada seria dizer que os direitos fundamentais só teriam sentido se previstos constitucionalmente. Nos termos do $\$ 2^{\circ}$ do artigo $5^{\circ}$ da Constituição Federal (BRASIL, 2019, online), "os direitos e garantias expressos nesta Constituição não excluem outros decorrentes do regime e dos princípios por ela adotados, ou dos tratados internacionais em que a República Federativa do Brasil seja parte”. Neste sentido, os direitos e garantias da constituição não fazem com que outros que já existem ou vierem a existir sejam excluídos 
por não estarem expressamente nela. Os direitos fundamentais formam um mínimo de direitos garantidos, estando o legislador ordinário autorizado a acrescentar outros. $\mathrm{O}$ rol constitucional é meramente exemplificativo.

Com a Emenda Constitucional n. 45/2004, o $\$ 3^{\circ}$ do artigo $5^{\circ}$ da Constituição Federal, buscou um aperfeiçoamento da proteção dos direitos humanos como decorrência da tutela avançada dos direitos fundamentais. Assim é que, os tratados e convenções internacionais que versarem sobre direitos humanos aprovados com quórum qualificado previsto no citado artigo passam a ter o status de emenda constitucional.

Resume, Gregório Assagra de Almeida (2008, p. 310),

Direitos fundamentais são todos os direitos, individuais ou coletivos, previstos expressa ou implicitamente em determinada ordem jurídica e que representam os valores maiores nas conquistas históricas dos indivíduos e das coletividades, os quais giram em torno de um núcleo fundante do próprio Estado Democrático de Direito, que é justamente o direito à vida e a sua existência com dignidade.

Conclui-se, portanto, que os direitos humanos e/ou direitos fundamentais têm como núcleo a proteção da dignidade da pessoa humana.

Neste contexto, pode-se incluir o direito ao registro, referente ao Registro Civil das Pessoas Naturais, entre os direitos humanos: um poder-dever que garante um mínimo necessário e imprescindível à dignidade humana.

\section{O REGISTRO CIVIL DAS PESSOAS NATURAIS COMO UM DIREITO COLETIVO}

A Constituição Federal de 1988 constitui-se, sem dúvidas, na consagração de conquistas jurídicas, sociais e políticas, de longe, as mais importantes da história do Brasil e mais transformadoras.

Uma das grandes novidades da Constituição Federal foi a inserção da tutela jurídica do Direito Coletivo na teoria dos direitos e garantias constitucionais fundamentais. Inovou, assim, na proteção dos direitos e interesses massificados, conferindo-lhes dignidade constitucional própria de uma nação democrática que pretenda transformar a realidade social.

Concordando com Gregório Assagra de Almeida, com a vigência da Constituição de 1988, não houve a recepção da summa divisio clássica Direito Público e Direito Privado. A nova summa divisio constitucionalizada no país é Direito Individual e Direito Coletivo. Trata-se de summa divisio constitucionalizada relativizada, pois no topo encontra-se o Direito Constitucional, representado pelo seu objeto formal, a Constituição, composta tanto de normas de Direito Individual, quanto de normas de Direito Coletivo.

Nos dizeres de Gregório Assagra de Almeida (2008, p. 361 e 362),

O Capítulo I do Título II da CF/88 explicita o fundamento da nova summa divisio ao fazer constar do texto constitucional, em cláusula expressa, as seguintes expressôes: Dos Direitos e dos Deveres Individuais e Coletivos. Outros argumentos existem, 
cabendo destacar a incompatibilidade do dualismo clássico, que separa Estado da sociedade, com o Estado Democrático de Direito e a necessidade de se estabelecer enquadramento metodológico dos direitos, levando-se em conta os planos da titularidade e, especialmente, o plano da proteçáo e da efetivação do direito, para os quais se volta a ciência jurídica, de dimensão prática estabelecida, em tempos atuais, pelo pós-positivismo jurídico.

A summa divisio implantada na Constituição Federal Brasileira de 1988 é a Direito Coletivo e Direito Individual.

Pois bem, o que nos interessa aqui é o Direito Coletivo. Conceitua o instituto, Gregório Assagra de Almeida (2008, p. 437),

Direito coletivo pode ser conceituado como a parte integrante da teoria constitucional dos direitos fundamentais, que compóe um dos blocos do sistema jurídico brasileiro e se integra pelo conjunto de princípios, garantias e regras disciplinadoras dos direitos ou interesses difusos, dos direitos ou interesses coletivos em sentido estrito, dos direitos e interesses individuais homogêneos e dos interesses coletivos legítimos.

Os direitos coletivos são de três espécies: direitos ou interesses difusos; direitos ou interesses coletivos em sentido estrito; e, direitos ou interesses individuais homogêneos.

O Código de Defesa do Consumidor, no parágrafo único do art. 81, nos dá o conceito do que são esses direitos.

O art. 81, parágrafo único, inciso I, do CDC (BRASIL, 2019, online), dispóe que são "interesses ou direitos difusos, assim entendidos, para efeitos deste Código, os transindividuais, de natureza indivisível, de que sejam titulares pessoas indeterminadas e ligadas por circunstâncias de fato".

Gregório Assagra de Almeida (2008, p. 481 e 482) aduz,

Utilizando os critérios seguidos pelo CDC, verifica-se que, sob o aspecto subjetivo, os direitos ou interesses difusos têm como titulares pessoas indeterminadas e indetermináveis.

Pelo aspecto objetivo, pertinente ao objeto dessa categoria de direitos ou interesses coletivos, observa-se que eles são indivisíveis.

Por fim, pelo aspecto origem, verifica-se que os direitos ou interesses difusos têm origem comum, geralmente, sem vínculo jurídico prévio entre seus titulares.

Assim, pode-se dizer que essa espécie de direito é transindividual (metaindividual ou supraindividual), indivisível e pertencente à coletividade formada por pessoas ligadas por uma situação de fato.

São considerados direitos ou interesses coletivos stricto sensu pelo CDC, art. 81, parágrafo único, inciso II (BRASIL, 2019, online), “os transindividuais de natureza indivisível de que seja titular grupo, categoria ou classe de pessoas ligadas entre si ou com a parte contrária por uma relação jurídica base”. 
Nos dizeres de Gregório Assagra de Almeida (2008, p. 483),

No sentido dos critérios do CDC, os direitos coletivos são, sob o aspecto subjetivo, pertencentes a um grupo, categoria ou classe de pessoas indeterminadas, mas determináveis.

Sob o aspecto objetivo, por serem transindividuais e metaindividuais, são indivisíveis e indistinguíveis na forma dos difusos.

Sob o aspecto origem, seus titulares - grupo, categoria ou classe de pessoas - estão ligados entre si por uma prévia relação jurídica base, que é mantida entre si ou com a parte contrária.

Essa espécie de direito, portanto, é transindividual, de natureza indivisível, pertencente a um grupo, classe ou categoria de pessoas indeterminadas, mas determináveis, e que tem origem em relação jurídica base que não se confunde com a relação jurídica controvertida que será analisada no processo coletivo. Essa relação jurídica base é preexistente à lesão ou ameaça de lesão ao direito do grupo, classe ou categoria.

Por fim, o Código de Defesa do Consumidor, em seu art. 81, parágrafo único, inciso III (BRASIL, 2019, online), de forma sucinta, conceitua os direitos individuais homogêneos como sendo "os decorrentes de origem comum".

Completa o conceito, Gregório Assagra de Almeida (2008, p. 485),

Usando dos critérios do CDC, extrai-se que, pelo aspecto subjetivo, os direitos ou interesses individuais homogêneos têm como titulares pessoas perfeitamente individualizadas, que podem ser indeterminadas, mas facilmente determináveis.

Pelo aspecto objetivo e pelo caráter predominantemente individualizado são eles divisíveis e distinguíveis entre seus titulares.

Pelo aspecto origem são eles de origem comum. Em relação à origem comum é que há ponto de semelhança entre os direitos ou interesses individuais homogêneos e os direitos ou interesses difusos, pois ambas as categorias, diferentemente dos direitos coletivos em sentido estrito, em que se exige prévia relação jurídica-base, geralmente nascem ligadas pelas mesmas circunstâncias, não obstante sejam, quanto à titularidade e ao objeto, totalmente distinguíveis.

Os direitos individuais homogêneos são apenas acidentalmente coletivos, que, em razão de sua origem comum, podem ser tutelados de forma coletiva. Aqui há um vínculo em comum entre pessoas identificadas ou identificáveis, sendo o direito ou interesse divisível.

Portanto, analisando o Registro Civil de Pessoas Naturais e seus objetivos, pode-se concluir que se trata de um direito coletivo, mais especificamente do tipo difuso, pois se trata de direito indivisível pertencente a titulares indetermináveis, a todos os indivíduos indistintamente. 


\section{0 REGISTRO CIVIL DAS PESSOAS NATURAIS E O SEU PAPEL NA EFETIVIDADE DOS DIREITOS FUNDAMENTAIS}

Seguindo a evolução dos tempos, o poder estatal passou a delegar os serviços de registro a pessoas físicas selecionadas em exame de títulos e provas, bem como corrigi-lo e fiscalizá-lo em conformidade com os ditames legais. À luz do artigo $1^{\circ}$ da Lei de Registro Públicos (Lei n. 6.015/73), os serviços concernentes foram estabelecidos pela lei civil para publicidade, autenticidade, segurança e eficácia dos atos jurídicos. Depreende-se dos textos constitucional e legal que fazer documentos públicos, autenticar fatos e dar publicidade jurídica a determinados fatos e situaçóes relevantes para a sociedade constituem funçóes do Estado. No entanto, a própria Lei Maior dispóe que os serviços notariais e de registro são exercidos por pessoas físicas, em caráter privado, por delegação do Poder Público (artigo 236 da CF/88). Por sua vez, o artigo $3^{o}$ da Lei n. 8.935/94, que complementa a norma constitucional, estabelece que o notário ou tabelião, e o registrador ou oficial de registro, são profissionais do direito, dotados de fé pública, a quem é delegado o exercício das atividades supracitadas.

Neste sentido, cabe ressaltar que, os Registros Públicos em geral, como o próprio nome já diz, trata-se de serviço público, porquanto alcança um número indeterminado de pessoas que a todos interessam. Importa também ao próprio Estado, o que traduz um relevante interesse público. Todavia, tal serviço é prestado por particulares, ditos delegatários, aos quais o Poder Público delega tal prestação sob um regime que lhes é peculiar.

Sobre o serviço registral disposto na Lei n. 6.015/73, Walter Ceneviva (2010, p. 55) acrescenta

Os serviços concernentes aos registros relacionados no art. $1^{\circ}$ são desempenhados em serventias confiadas a delegados do Poder Público (art. 20). A estes o Estado delega a função de receber, conferir e transpor para seus livros declaraçóes orais ou escritas sobre fatos jurídicos e negócios jurídicos dos interessados ou apresentantes. Feitos os registros, passam ao conhecimento de todos os que queiram ou devam ser informados a respeito, exceto os submetidos, por lei, ao sigilo.

Pois bem, o Registro Civil de Pessoas Naturais é um serviço público regulado, basicamente, pelas Lei n. 6.015/73, Lei n. 8.935/94 e pelas Normas de Serviço editadas pelas Corregedorias Gerais de Justiça Estaduais, tendo a atribuição de garantir a publicidade, autenticidade, segurança e eficácia do atos e fatos ocorridos ao longo da vida, bem como das questốes de estado da pessoa natural.

O Registro Civil das Pessoas Naturais (RCPN), como seu próprio nome indica, tem como foco de interesse a pessoa física ou natural, ou seja, o indivíduo, o ser humano. Cabem ao registrador civil o registro e a publicidade de fatos e negócios jurídicos inerentes à pessoa física, desde o seu nascimento até a sua morte, tendo em vista que tais fatos e atos repercutem não apenas na esfera do indivíduo, mas interessam a toda sociedade.

Como bem resume Luiz Guilherme Loureiro (2016, p. 140), 
Em suma, o Registro Civil das Pessoas Naturais é o repositório dos atos de estado civil, o mecanismo apto para constataçáo e publicaçáo dos fatos e atos que definem o estado de uma pessoa física. Vimos acima que cabe ao Estado, por meio do Direito, a tutela da identidade e dos atributos dos indivíduos. Esta proteção não se limita à segurança do corpo e do espírito da pessoa humana, mas também ao livre e pleno desenvolvimento de sua personalidade. Hoje, o principal núcleo de proteçâo da ordem jurídica é a pessoa humana e, pelo fato desse ser humano ser revestido de personalidade própria, quando se tutela a pessoa, náo se pode retirar do âmbito de proteção a personalidade, já que ambas estão relacionadas. Portanto, ao lado da igualdade formal, o direito também tutela a igualdade substancial, o que apenas é possível com a identificação do estatuto legal particular de cada indivíduo, que é dado por seu estado pessoal.

A importância do Registro Civil de Pessoas Naturais é de tal forma que seu serviço será prestado, além dos dias normais, aos sábados, domingos e feriados.

Nos termos do artigo $4^{\circ}$ e seu $\$ 1^{\circ}$ da Lei n. 8.935/94 (BRASIL, 2019, online),

Art. $4^{\circ}$. Os serviços notariais e de registro serão prestados, de modo eficiente e adequado, em dias e horários estabelecidos pelo juízo competente, atendidas as peculiaridades locais, em local de fácil acesso ao público e que ofereça segurança para o arquivamento de livros e documentos.

$\$ 1^{\circ}$. O serviço de registro civil das pessoas naturais será prestado, também, nos sábados, domingos e feriados pelo sistema de plantão.

Em face da sua importância e do fato de tratar de eventos urgentes e relacionados à existência da pessoa humana, o RCPN é o único serviço que trabalha de forma contínua, sem interrupção. Podem ser lavrados registros em qualquer dia e horário, inclusive aos finais de semana, sem que se verifique nulidade ou irregularidade dos assentos. Com efeito, ao contrário do que sucede no Registro de Imóveis e outros serviços, não incidem a proibição, nem a cominação de nulidade, no tocante ao Registro Civil das Pessoas Naturais, de atos de registro lavrados fora das horas regulamentares, ou em dias que não haja expediente.

De forma geral, as serventias de RCPN ficam abertas de segunda-feira a sexta-feira, ficando de plantão nos sábados, domingos e feriados. Os horários de funcionamento são fixados pelo juiz competente de acordo com as normas de cada Estado.

Portanto, pode-se dizer que o registro civil de pessoas naturais tem como função o registro de fatos e atos importantes para a identificação e proteção da pessoa natural e para sua vida jurídica e social, tais como o nascimento, casamento, óbito, interdição, emancipação, opção de nacionalidade, entre outros atos importantes relacionados ao estado da pessoa. Enfim, facilmente se constata que o serviço em apreço tem como elemento o ser humano e a proteção à sua dignidade é visível nos atos que o registrador pratica.

\subsection{Registro de Nascimento}

O nascimento com vida faz surgir a pessoa natural e o atributo da personalidade jurídica (artigo 2o do Código Civil), ou seja, o principal efeito jurídico do nascimento com vida é a aquisição da personalidade. Logo, o nascimento é um evento natural do qual emanam 
atributos, tais como, o nome, o estado, o domicílio, o patrimônio ou ainda a capacidade jurídica, daí a relevância de determinar e de comunicar a todos os membros da sociedade a partir de que momento um indivíduo adquire personalidade, nasce. Esta função, desempenhada pelo registrador civil, diz respeito a um questão fundamental do direito civil.

Os direitos da personalidade só foram admitidos, a princípio, como universais e inerentes à pessoa, a partir da Declaração dos Direitos do Homem de 1948, após longa evolução histórica. Vários tratados internacionais procuraram efetivar tais direitos em diversos países. Esses direitos da personalidade são as prerrogativas de conteúdo extrapatrimonial, inalienáveis, perpétuas e oponíveis erga omnes, que correspondem a toda pessoa por sua condiçâo de tal, a princípio, desde seu nascimento até a sua morte, e das quais não pode ser privada pelo Estado nem por outros particulares porque isso implicaria desrespeito a personalidade e consequentemente aos direitos fundamentais inerentes à pessoa humana. Os direitos personalíssimos constituem uma inconfundível categoria de direitos subjetivos essenciais, que pertencem à pessoa simplesmente por sua condição humana e que se encontram ligados ao indivíduo.

Tais direitos existem e são oponíveis erga omnes independentemente do registro e da publicidade do evento "nascimento". Não obstante, as qualidades das pessoas devem ser constatadas para que possam ser provadas e levadas ao conhecimento de terceiros.

O registro de nascimento é o primeiro ato de cidadania da pessoa natural. Com ele, o ser humano tem a possibilidade de exercer os direitos mais básicos indispensáveis à sua dignidade.

Neste sentido, Luiz Guilherme Loureiro (2016, p. 181),

[...] Mas o principal, e que serve de origem para algum deles, é o registro de nascimento que por isso é denominado de primeiro documento da cidadania: trata-se de documento indispensável para a constatação das qualidades pessoais, não apenas pela prova das situaçóes jurídicas, como também pela publicidade que garante a oponibilidade dessas situaçóes.

Acrescenta ainda, Mario de Carvalho Camargo Neto e Marcelo Salaroli de Oliveira (2014, p. 112),

É óbvio que ninguém precisa de uma certidão lavrada em cartório para ter a certeza de que está diante de uma pessoa humana, portanto, diante de um titular de direitos e deveres. No entanto, sem a certidão de nascimento, não é possível individualizar aquela pessoa; sem a certidão, não se sabe seu nome, sua idade, sua nacionalidade, sua filiação, enfim, não se sabe quem é.

Por isso, pode-se dizer que o registro civil de nascimento é um ato simples, sem maiores formalidades, desburocratizado e gratuito, porém sua importância é inegável, pois por meio dele emanam todos os demais direitos inerentes ao exercício da cidadania. Dessa forma, fica claro que o registro de nascimento é o suporte para todos os demais atos da vida civil de qualquer pessoa.

As principais características do registro de nascimento são: a gratuidade (por força constitucional do artigo 5º, inciso LXXVI, e pelo artigo 30 da Lei de Registros Públicos, por ser o registro e a certidão de nascimento considerados atos essenciais ao exercício da 
cidadania); perpetuidade (os registros de nascimento são conservados pelas serventias para sempre. Incumbe ao registrador conservar os livros e documentos que instruírem os registros em local apropriado, protegendo-os de qualquer fator que possa destruí-los, inclusive o tempo); obrigatoriedade (nos termos do artigo 51 da Lei n. 6.015/73, todo nascimento que ocorrer no território nacional deverá ser dado a registro. Quer a lei que todo nascimento seja objeto de registro).

Ainda sob a ótica da cidadania, o registro civil de nascimento traz os três elementos que identificam a pessoa natural, quais sejam: seu nome, seu domicílio e seu estado, este composto pelo político (concernente à naturalidade e à nacionalidade), individual (idade, sexo e capacidade) e, por fim, familiar (filiação, parentesco). Deste modo, resta claro que o registro de nascimento carrega os principais elementos identificadores e a carga genealógica da pessoa natural, o que lhe franqueia conhecer seus ancestrais e sua origem familiar. Trata-se de direito fundamental da pessoa humana, portanto.

Neste sentido, é de se notar a importância do nome na identificação e individuação das pessoas. Segundo, Luiz Guilherme Loureiro (2016, p. 169)

O nome, invocador de toda uma história, de um passado e de uma tradição familiar, continua a ser um importante elemento de identificação e, mais do que isso, um direito da personalidade. Pode-se afirmar que, nos dias atuais, os dois sistemas coexistem: o nome, para uso dos homens; o número para uso das máquinas. Com efeito, mais do que um mero sinal identificador do indivíduo, o nome constitui um direito inerente ao ser humano, de tal forma que não pode existir pessoa natural sem nome, tampouco é possível a sua renúncia.

A atribuição do nome à pessoa natural é um direito fundamental essencial. Dessa forma, o nome é o sinal que identifica e individualiza a pessoa no grupo familiar e na sociedade. É tâo importante que o artigo 58 da Lei n. 6.015/73 dispóe que o prenome é definitivo. No entanto, este mesmo dispositivo estabelece a exceção ao princípio da imutabilidade do prenome no caput e no $\$ 1^{\circ}$, além de outras exceçóes previstas em lei.

Ocorria dúvida na questão do nome no caso de criança nascida morta (natimorto). Neste caso, não é feito o registro de nascimento. Segundo o artigo $53, \$ 1^{\circ}$ da Lei n. 6.015/73, o registro da criança nascida morta deverá ser feito no Livro C Auxiliar, com os "elementos que couberem". A lei não veda que os pais declarem no registro de criança nascida morta o nome e sobrenome do registrando. Pelo contrário, o artigo $53, \$ 1^{\circ}$, da Lei n. 6.015/73 dispóe que, no caso de a criança ter nascido morta, o registro deve ser feito no Livro C Auxiliar com os elementos que couberem, e é certo que o nome é um dos elementos do registro de óbito (artigo $80, \$ 5^{\circ}$, da Lei n. 6.015/73) e também do assento de nascimento (artigo 54, n. 4, da Lei n. 6.015/73). Apesar do nascituro não possuir personalidade jurídica, a questão deve ser analisada não sob a ótica dos direitos do nascituro ou do natimorto, mas sim sob os direitos da gestante ou dos genitores e sob o princípio da dignidade da pessoa humana. Nesse sentido deve ser entendido o Enunciado 1 da I Jornada de Direito Civil do Conselho da Justiça Federal (BRASIL, 2019, online): "1 - Art. 2. A proteção que o Código defere ao nascituro alcança o natimorto no que concerne aos direitos da personalidade, tais como: nome, imagem e sepultura".

Ainda acerca do nome, há de se frisar o importante papel do registrador no momento da lavratura do registro de nascimento. De acordo com a artigo 55, parágrafo único, da Lei 
6.015/73, os oficiais de registro não registrarão prenomes suscetíveis de expor ao ridículo seus portadores. Portanto, facilmente se constata que atribuir nome a outrem é coisa séria. Logo, deve o oficial de registro impedir qualquer tentativa do declarante no sentido de se tentar registrar algum nome capaz de expor seu portador a situaçóes vexatórias. Sem sombra de dúvidas, esse poder atribuído ao oficial para impedir tal intento lamentável representa uma salvaguarda aos direitos da personalidade daquele que está preste a ter o nascimento registrado.

Uma questão que merece destaque apontar aqui é a recente decisão (09/05/2017) do STJ no Recurso Especial n. 1626739/RS ${ }^{1}$, acerca da possibilidade de alteração de nome e gênero no assento de registro civil de transexual, mesmo sem a realização de procedimento cirúrgico de redesignação de sexo. O Superior Tribunal, por maioria, deu provimento ao recurso especial interposto autorizando a retificaçáo do registro civil independente da cirurgia de transgenitalização sob o fundamento do princípio fundamental da dignidade da pessoa humana. Sob essa ótica, houve resguardo aos direitos fundamentais das pessoas transexuais não operadas à identidade (tratamento social de acordo com sua identidade de gênero), à liberdade de desenvolvimento e de expressão da personalidade humana (sem indevida intromissão estatal), ao reconhecimento perante a lei (independentemente da realização de procedimentos médicos), à intimidade e à privacidade (proteçâo das escolhas de vida), à igualdade e à não discriminação (eliminação de desigualdades fáticas que venham a colocá-los em situação de inferioridade), à saúde (garantia do bem-estar biopsicofísico) e à felicidade (bem-estar geral).

Em julgamento no Supremo Tribunal Federal, o assunto foi decidido em sede do Recurso Extraordinário n. $670422^{2}$, julgado no segundo semestre de 2018 e provido pela maioria dos votos. Mantida a possibilidade de alteração de gênero no assento de registro civil de transexual, mesmo sem a realização de procedimento cirúrgico de redesignação de sexo.

Ainda no assunto, em 28 de abril de 2016, foi editado o Decreto n. 8.727, da Presidência da República (BRASIL, 2019, online), o qual dispóe sobre o uso do nome social e o reconhecimento da identidade de gênero de pessoas travestis e transexuais no âmbito da administração pública federal direta, autárquica e fundacional. Tal Decreto ensejou a possibilidade de requerimento, pelas pessoas travestis e transexuais, de terem o nome social incluído no Cadastro de Pessoas Físicas (CPF), conforme Instrução Normativa 1.718/2017 da Receita Federal do Brasil (RFB, 2019, online).

Porém, outros elementos identificadores lançados nos assentos registrais também são de suma importância. Um desses elemento é a nacionalidade.

Entende-se por nacionalidade o vínculo jurídico existente entre o Estado e o indivíduo, por meio do qual este se torna parte integrante do povo daquele. Cada Estado deve definir quem são seu nacionais. No caso do Brasil, é a própria Constituição, com exclusividade, quem define os critérios para aquisição da nacionalidade brasileira. $\mathrm{O}$ artigo 12, inciso I, da Constituição Federal de 1988, estabelece quem são os brasileiros natos, ou seja, aqueles com nacionalidade originária brasileira. Segundo o critério jus soli, é brasileiro os nascidos no Brasil, ainda que de pais estrangeiros, desde que estes não estejam a serviço de seu pais. Pois bem,

1 BRASIL. Superior Tribunal de Justiça. RECURSO ESPECIAL: REsp 1626739 RS 2016/02455869. Quarta Turma. Decisão em 09/05/2017. DJe 01/08/2017. Disponivel em: https://stj.jusbrasil.com.br/ jurisprudencia/484087877/recurso-especial-resp-1626739-rs-2016-0245586-9?ref=juris-tabs. Acesso em 06 jun. 2019.

2 BRASIL. Supremo Tribunal Federal. RECURSO EXTRAORDINÁRIO 670422. Procedência Rio Grande do Sul. Rel. Min. Dias Toffoli. DJ Nr. 169 do dia 20/08/2018. Disponivel em: http://portal.stf.jus.br/processos/detalhe. asp?incidente $=4192182$. Acesso em 06 jun. 2019. 
pode-se dizer que nascimento com vida dentro do território nacional confere ao nascido um vínculo jurídico-político de cidadão brasileiro para com a nossa pátria.

Neste sentido, José Afonso da Silva (2004, p. 320).

\begin{abstract}
Ora, a nacionalidade é um direito fundamental do homem, sendo inadmissível uma situação independente da vontade do indivíduo, que o prive desse direito. A Declaraçáo Universal dos Direitos Humanos bem reconhece, quando estatui que toda pessoa tem direito a uma nacionalidade e ninguém será arbitrariamente privado de sua nacionalidade, nem do direito de mudar de nacionalidade.
\end{abstract}

Outra situação muito recorrente que representa um avanço à proteção da dignidade da pessoa humana é o reconhecimento da paternidade feito direta e administrativamente pela serventia extrajudicial, sem a necessidade de se passar pela demora de um processo jurisdicional. O Provimento 16 de 2012 do Conselho Nacional de Justiça (BRASIL, 2019, online) veio para facilitar a atribuição do vínculo de paternidade àqueles que foram registrados apenas com o nome da genitora.

Segundo tal provimento, a qualquer momento, mesmo após a lavratura do registro, a mãe poderá comparecer pessoalmente perante o oficial de registro civil de pessoas naturais e apontar o suposto pai, enquanto o filho não adquirir a maioridade. Quando completar dezoito anos, o próprio filho poderá comparecer pessoalmente perante o registrador e apontar o suposto pai. A partir daí, o registrador seguirá o procedimento simplificado da Lei n. 8.560/1992 (BRASIL. 2019, online).

Pode ocorrer, ainda, que o próprio pai procure o Cartório de Registro Civil das Pessoas Naturais para reconhecer espontaneamente a paternidade de filho cujo vínculo parental não foi estabelecido no registro de nascimento. $\mathrm{O}$ reconhecimento de paternidade deve ser declarado em documento particular que ficará arquivado em cartório. A própria serventia pode confeccionar o termo de reconhecimento de filho, contendo os dados identificadores do pai e do filho reconhecido, que deverá ser assinado por ambos, quando o reconhecido tiver completado a maioridade. Caso o filho reconhecido seja menor, o termo será assinado pelo pai e pela genitora.

Indubitavelmente, isso representa mais uma amostra da atribuição de direitos fundamentais à pessoa humana, pela via desburocratizada do Registro Civil das Pessoas Naturais, sem perder de vista a segurança jurídica, eficácia, autenticidade e publicidade dos atos praticados.

\title{
4.1.1. Convênio entre o serviço de Registro Civil de Pessoas Naturais e a maternidade e o Provimento 13 do CNJ
}

Para dar uma maior efetividade aos direitos fundamentais inerentes ao Registro Civil das Pessoas Naturais, existe um convênio entre as serventias e as maternidades, visando facilitar o registro de nascimento dos recém-nascidos e acabar com o sub-registro nos Estados brasileiros.

O CNJ editou o Provimento 13 de 2010 (BRASIL, 2019, online) que tem por finalidade a erradicação do sub-registro civil de nascimento, mediante a instituiçấo de convênios entre os serviços de registro civil de pessoas naturais e maternidades, para que os registros das crianças nascidas nestes estabelecimentos hospitalares sejam feitos em 
"tempo real", isto é, no mesmo dia em que ocorrer o nascimento, com a entrega imediata da certidão concernente.

Desse modo, evita-se que os pais tenham que se locomover até a unidade de serviço competente para proceder à declaração do nascimento e providenciar tal registro. A distância entre a maternidade e os cartórios, a falta de condiçóes econômicas dos pais para arcarem com o transporte até a serventia, além de outros fatores, contribuem para o alto número de sub-registro nas regióes mais pobres do Brasil, prejudicando o exercício da cidadania e menosprezando o princípio da dignidade da pessoa humana.

De acordo com o programa são criadas as chamadas "Unidades Interligadas", situadas nas maternidades conveniadas que interligam o hospital às serventias de registro civil por meio de salas, devidamente aparelhadas, utilizando-se de sistema informatizado conectado à internet.

Um preposto da serventia (ou funcionário devidamente treinado do hospital) permanecerá diariamente nesta unidade, na qual procederá à recepção dos dados necessários ao registro do nascimento e sua remessa ao cartório, por meio da internet. Recebidos os dados na serventia, será lavrado o registro de nascimento e enviada a respectiva certidão à unidade interligada. A certidão será então emitida na maternidade e entregue ao genitor, a fim de que a mãe e/ou a criança receba alta já com o seu primeiro documento de cidadania em mãos.

Segundo Luiz Guilherme Loureiro (2016, p. 217),

O primeiro passo para a implementação do programa é o estabelecimento do convênio com a maternidade local, para que seja reservada sala apropriada para o funcionamento da unidade interligada, bem como equipamentos necessários (computador, programa informático, acesso à internet, impressora e certificado digital). As pessoas responsáveis pela coleta, envio de dados e impressáo da certidáo de nascimento devem ser prepostas do cartório ou da maternidade. Neste último caso, deve ser treinada pelo registrador acerca das cautelas e procedimentos necessários para garantir a exatidão $\mathrm{e}$ veracidade dos dados exigidos por lei. O registrador não responde pelos danos causados aos usuários pelo preposto da maternidade, já que não possui com o mesmo qualquer vínculo jurídico, não se aplicando as figuras da culpa in eligendo ou culpa in vigilando.

Cumpre ressaltar que a Unidade Interligada que conecta estabelecimento de saúde aos serviços de registro civil não é considerada sucursal da serventia, o que é vedado pela Lei n. 8.935/94, uma vez que, pode se relacionar com diversos cartórios situados no município em que se localiza o hospital.

A permanência do registrador ao Sistema de Unidades Interligadas não é obrigatória. De qualquer forma, o registro de nascimento e a entrega da certidão competente aos pais que ainda se encontram no hospital é um serviço de relevância pública e deve ser garantido, ainda que por outros mecanismos.

\subsection{Registro de Casamento}

É no Registro Civil de Pessoas Naturais que se lavram um dos mais importantes e solenes atos da vida civil da pessoa humana: o casamento. 
O casamento é um dos modos de constituição da família e se caracteriza pela comunhão plena de vida, com base na igualdade de direitos e deveres dos cônjuges. A Constituiçấo de 1988 , em seu artigo $226, \$ 5^{\circ}$, dispóe que os direitos e deveres referentes à sociedade conjugal são exercidos igualmente pelo homem e pela mulher. A instituição do matrimônio é protegida pela Constituição, que veda qualquer interferência de pessoa de direito público ou privado na vida familiar.

Logo, denota-se que o casamento tem um caráter instrumental, porquanto representa, ao mesmo tempo, forma de constituição de família, bem como meio jurídico-legal para que duas pessoas se unam com propósitos comuns, a fim de alcançarem a realização plena e felicidade pessoal.

Trata-se, pois, de verdadeiro direito humano fundamental.

Por se tratar de uma importante alteração do estado da pessoa natural acarretando também consequências jurídicas que vai além do âmbito de vida do casal, o casamento deve ser registrado no Livro B ou, a depender, Livro B-Auxiliar, para que possa ganhar publicidade irrestrita e chegar ao alcance de toda a sociedade.

Cumpre destacar que o Supremo Tribunal Federal, no julgamento conjunto da ADPF n. 132/RJ e da ADI n. 4.277/ $\mathrm{DF}^{3}$, conferiu ao artigo 1.723 do Código Civil interpretação conforme à Constituiçáo para dele excluir todo significado que impeça o reconhecimento da união contínua, pública e duradoura entre pessoas do mesmo sexo como entidade familiar, entendida esta como sinônimo perfeito de família. Ou seja, o STF deixa claro que o instituto da união estável se aplica tanto aos casais heterossexuais, quanto às relaçóes entre pessoas do mesmo sexo.

De acordo com Luiz Guilherme Loureiro (2016, p. 260),

\begin{abstract}
$\mathrm{Na}$ ação supracitada, o STF deixou assentado que a Constituição não proíbe a formação de família por pessoa do mesmo sexo. Pelo contrário, os princípios nela consagrados, notadamente o da liberdade, da igualdade e da dignidade da pessoa humana, garantem a cada pessoa a livre escolha de seu parceiro afetivo e sexual e os companheiros em razão de sua orientação sexual.
\end{abstract}

Neste sentido, é notório concluir que se a lei garante a possibilidade da conversão da união estável em casamento, em se tratando de casais heterossexuais, o mesmo direito vale para os casais homoafetivos. E, por igual razão, é possível o casamento direto entre homossexuais. Confirmando tal entendimento, o Conselho Nacional de Justiça editou a Resolução n. 175 de 2013 (BRASIL, 2019, online), que veda a recusa de celebração de casamento civil ou de conversão de união estável em casamento entre pessoas do mesmo sexo.

\title{
4.3. Registro de Óbito
}

A personalidade civil se extingue com a morte. A morte é um fato natural que produz efeitos jurídicos relevantes e, por isso, deve ser tornada pública aos demais membros da

3 BRASIL. Supremo Tribunal Federal. AÇÃO DIRETA DE INCONSTITUCIONALIDADE ADI 4277 DF. Disponivel em: https://stf.jusbrasil.com.br/jurisprudencia/20627236/acao-direta-de-inconstitucionalidade-adi-4277-df-stf. Acesso em 06 jun. 2019. 
comunidade, não só para prova da não mais existência física e jurídica da pessoa, como para que os efeitos jurídicos derivados de tal evento possam ser oponíveis erga omnes.

Em decorrência da morte surgem diversas situaçóes jurídicas, as quais, entretanto, exigem prova do falecimento e esta é o registro do óbito, refletido através da certidáo de óbito. Desta forma, se prova a morte pela certidão extraída do assento de óbito.

Portanto verifica-se o papel preponderante do Registro Civil de Pessoas Naturais quando do registro de óbito no resguardo dos direitos fundamentais. Há, não somente no assento de óbito mas em qualquer ato praticado pelo RCPN, um papel difuso na implementação de políticas públicas pelo Estado, pois os dados recolhidos por tais serventias na realização de seus atos são repassados ao Poder Público que, por meio deles, pratica esforços na consecução de programas destinados à realização de interesses públicos nas mais diversas áreas. Por exemplo, por meio dos dados constantes dos registro de óbitos, o Poder Público tem a possibilidade de realizar estudos, pesquisas e investimentos na área de saúde pública. Cumpre ainda salientar que todas as informaçóes prestadas pelo RCPN ao Poder Público são destituíveis de qualquer custo, além do que este tem acesso ao dados repassados de forma precisa.

\subsection{A imunidade dos emolumentos do registro de nascimento e óbito e a primeira via da certidão respectiva}

Devido à importância do registro civil de nascimento e de óbito, a Constituição Federal de 1988 previu, no seu artigo 5º, inciso LXXVI, que o assento de nascimento e de óbito são gratuitos e, ainda, que realizados fora dos prazos legais, sobre eles não incidirão eventuais multas.

Todas as pessoas humanas, sem distinção, passam pelo Registro Civil de Pessoas Naturais, ao menos duas vezes na vida: quando nascem e quando morrem.

Nos termos do artigo 45 da Lei n. 8.935/94 (BRASIL, 2019, online), "são gratuitos os assentos do registro civil de nascimento e o de óbito, bem como a primeira certidão respectiva”.

Não há sentido na cobrança, tendo em vista que os atos relativos ao nascimento e ao óbito relacionam-se com a cidadania e com seu exercício. Se extrai dessa imunidade a facilidade de acesso ao registro civil, representando assim uma importante ferramenta destinada a reduzir sub-registro no Brasil, entre outras consequências.

Cumpre salientar que não apenas o registro de nascimento e óbito são isentos de emolumentos, mas também o casamento civil tem isenção declarada no artigo $226, \$ 1^{\circ}$ da Constituição Federal e no artigo 1.512, parágrafo único, do Código Civil, pois impóem a todos a gratuidade da celebração matrimonial, bem como, para os reconhecidamente pobres, a habilitação, o registro e a primeira certidão de casamento, conforme conceito legal. Neste ato, referente ao casamento, o benefício da gratuidade não é geral, mas direito subjetivo dos reconhecidamente pobres.

Tais isençôes são tão importantes que será extinta a delegação ao oficial de registro pelo seu descumprimento comprovado da gratuidade estabelecida pela Lei n. 9534/97. Portanto, mais uma amostra do importante papel do Registro Civil de Pessoas Naturais, contribuindo para o reconhecimento dos direitos fundamentais do ser humano. 


\section{CONSIDERAÇÕES FINAIS}

O Registro Civil das Pessoas Naturais tem como foco de interesse a pessoa física, o indivíduo, o ser humano. Cabe a este serviço o registro e a publicidade de fatos e negócios jurídicos inerentes à pessoa física, desde o seu nascimento até a sua morte, uma vez que tais fatos e atos repercutem não apenas na esfera do indivíduo, mas também interessam a toda a sociedade.

Hoje, o principal núcleo de proteção da ordem jurídica é a pessoa humana, pois o resguardo da dignidade da pessoa humana e da cidadania são fundamentos da República Federativa do Brasil.

É claro, porém, que há muito a se caminhar na busca da otimização da eficácia dos direitos fundamentais, principalmente tendo-se em mira aumentar a efetivação de tais direitos na prática. De nada adianta uma teoria primorosa sobre direitos desta natureza, enquanto presencia-se violaçóes destes no cotidiano.

O Registro Civil de Pessoas Naturais, ciente do papel fundamental que exerce, busca modernizar seus atos sempre na busca da efetivação da dignidade da pessoa humana. Nesse sentido, têm a todo tempo buscado a melhoria dos serviços prestados, a inclusáo de novas atribuiçóes e a modicidade das custas e emolumentos cobrados, sempre com o objetivo de garantir os direitos fundamentais à população brasileira. Claro que tal esforço é enviado sem perder de vista a segurança jurídica, a autenticidade, a eficácia e a publicidade dos atos praticados, que são, em última análise, os fins precípuos das instituições registrais e notariais como um todo.

Portanto, o fortalecimento do Registro Civil das Pessoas Naturais representa um avanço na proteção dos direitos fundamentais, na medida em que tais serviços prestados são de interesse de todos, sem distinção e tem como foco principal a salvaguarda do homem e sua dignidade.

\section{REFERÊNCIAS}

ALMEIDA, Gregório Assagra de. Direito Material Coletivo. Belo Horizonte: Del Rey, 2008.

BRASIL. Conselho Nacional de Justiça. I Jornada de Direito Civil. Enunciado 1. Disponível em: https://www.cjf.jus.br/enunciados/enunciado/647. Acesso em: 06 jun. 2019.

BRASIL. Conselho Nacional de Justiça. Provimento 13 de 2010. Disponível em: http:// www.cnj.jus.br/images/stories/docs_corregedoria/provimentos/provimento_13.pdf. Acesso em: 06 jun. 2019.

BRASIL. Conselho Nacional de Justiça. Provimento 16 de 2012. Disponível em: http:// www.cnj.jus.br/atos-normativos?documento=1299. Acesso em: 06 jun. 2019.

BRASIL. Conselho Nacional de Justiça. Resolução no 175 de 14/05/2013. Disponível em: http://www.cnj.jus.br/busca-atos-adm?documento=2504. Acesso em: 06 jun. 2019.

BRASIL. Constituiçáo da República Federativa do Brasil de 1988. Disponível em: http://www.planalto.gov.br/ccivil_03/constituicao/constituicao.htm. Acesso em: 06 jun. 2019. 
BRASIL. Decreto no 8.727, de 28 de abril de 2016. Disponível em: http://www.planalto.gov.br/ccivil_03/_Ato2015-2018/2016/Decreto/D8727.htm. Acesso em: 06 jun. 2019.

BRASIL. Lei no 6.015, de 31 de dezembro de 1973. Disponível em: http://www.planalto. gov.br/ccivil_03/leis/L6015compilada.htm. Acesso em: 06 jun. 2019.

BRASIL. Lei no 8.078, de 11 de setembro de 1990. Disponível em: http:/www.planalto. gov.br/ccivil_03/leis/18078.htm. Acesso em: 06 jun. 2019.

BRASIL. Lei no 8.560, de 29 de dezembro de 1992. Disponível em: http:/www.planalto. gov.br/ccivil_03/LEIS/L8560.htm. Acesso em: 06 jun. 2019

BRASIL. Leio 8.935, de 18 de novembro de 1994. Disponível em: http:/www.planalto. gov.br/CCivil_03/LEIS/L8935.htm. Acesso em: 06 jun. 2019.

BRASIL. Superior Tribunal de Justiça. RECURSO ESPECIAL: REsp 1626739 RS 2016/0245586-9. Quarta Turma. Decisão em 09/05/2017. DJe 01/08/2017. Disponível em: https://stj.jusbrasil.com.br/jurisprudencia/484087877/recurso-especial-resp-1626739-rs-2016-0245586-9?ref=juris-tabs. Acesso em: 06 jun. 2019.

BRASIL. Supremo Tribunal Federal. RECURSO EXTRAORDINÁRIO 670422. Procedência Rio Grando do Sul. Rel. Min. Dias Toffoli. DJ Nr. 169 do dia 20/08/2018. Disponível em: http://portal.stf.jus.br/processos/detalhe.asp?incidente=4192182. Acesso em: 06 jun. 2019.

BRASIL. Supremo Tribunal Federal. AÇÃO DIRETA INCONSTITUCIONALIDADE ADI 4277 DF. Disponível em: https://stf.jusbrasil.com.br/ jurisprudencia/20627236/acao-direta-de-inconstitucionalidade-adi-4277-df-stf. Acesso em: 06 jun. 2019.

BULOS, Uadi Lammêgo. Curso de Direito Constitucional. São Paulo: Saraiva, 2011.

CAMARGO NETO, Mario de; OLIVEIRA, Marcelo Salaroli de. CASSETARI, Christiano (Org.). Coleção cartórios: registro civil das pessoas naturais. São Paulo: Saraiva, 2014.

CENEVIVA, Walter. Lei dos Registros Públicos comentada. São Paulo: Saraiva, 2010.

DIDIER JR, Fredie; ZANETI JR, Hermes. Curso de Direito Processual Civil: Processo Coletivo. Salvador: JusPodivm, 2017.

DIP, Ricardo; JACOMINO, Sérgio. Registros Públicos e Legislação Correlata. São Paulo: Revista dos Tribunais, 2014.

DOMINGUES FILHO, José. Registros Públicos em cotejos e consertos. Campo Grande: Contemplar, 2014.

FERREIRA FILHO, Manuel Gonçalves. Direitos Humanos Fundamentais. São Paulo: Saraiva, 2006.

LENZA, Pedro. Direito Constitucional Esquematizado. São Paulo: Saraiva, 2014.

LOUREIRO, Luiz Guilherme. Manual de Direito Notarial: da atividade e dos documentos notarias. Salvador: JusPodivm, 2016.

LOUREIRO, Luiz Guilherme. Registros Públicos: Teoria e Prática. Salvador: JusPodivm, 2016. 
RECEITA FEDERAL DO BRASIL. Instrução Normativa RFB no 1718 , de 18 de julho de 2017. Disponível em: http://normas.receita.fazenda.gov.br/sijut2consulta/link. action?visao=anotado\&idAto=84588. Acesso em: 06 jun. 2019.

NEVES, Daniel Amorim Assumpção. Manual de Direito Processual Civil: volume único. Salvador: JusPodivm, 2017.

THEODORO JÚNIOR, Humberto. Curso de Direito Processual Civil: Volume II. Rio de Janeiro: Forense, 2016.

\section{Eloy Pereira Lemos Junior}

eloy.junior@uol.com.br

Doutor em direito pela UFMG (2007), possui mestrado e especializaçôes. Foi bolsista CAPES (2005) na Universidade de Lisboa, atualmente bolsista FUNDEP-UFMG (desde 2013). Avaliador de cursos de direito pelo INEP-MEC (desde 2010). Atualmente, é professor titular do mestrado e da graduação da Universidade de Itaúna (MG), titular na graduação da UEMG, UNIPAC. Tem experiência na área de direito, com ênfase em direito empresarial. Conselheiro editorial e parecerista de revistas especializadas em direito, palestrante, orientador de trabalhos científicos, participante de NDE - Núcleo Docente Estudante e de bancas diversas.

\section{Débora de Freitas Palhares}

deborafreitaspalhares@yahoo.com.br

Graduada em Direito pela PUC/MG; Pós Graduada em Direito Notarial e Registral pela AVM Faculdade Integrada; Pós Graduada em Português Jurídico pela AVM Faculdade Integrada; Pós Graduada em Direito Processual pela AVM Faculdade Integrada; Pós Graduada em Direito Tributário pela AVM Faculdade Integrada. Aluna do curso de Mestrado em Proteção dos Direitos Fundamentais pela Universidade de Itaúna, MG. 